\title{
Author Correction: Patenting and business outcomes for cleantech startups funded by the Advanced Research Projects Agency-Energy
}

Anna Goldstein (D), Claudia Doblinger (D), Erin Baker (D) and Laura Díaz Anadón

Correction to: Nature Energy https://doi.org/10.1038/s41560-020-00683-8, published online 14 September 2020.

In the version of this Analysis originally published, in the Acknowledgements, the support from the Belfer Center's Science, Technology, and Public Policy Program was mistakenly not mentioned; this information has now been added to the sentence beginning "We acknowledge funding from the.... All versions of the Analysis have been amended.

Published online: 25 September 2020

https://doi.org/10.1038/s41560-020-00713-5

(C) The Author(s), under exclusive licence to Springer Nature Limited 2020 